\title{
The Effect of World Fertility Scenarios on International Living Standards
}

\author{
Ross S. Guest \\ Griffith University \\ Australia \\ Ian M. McDonald \\ The University of Melbourne \\ Australia
}

\begin{abstract}
This paper applies a two good, multi-region Ramsey-Solow model to determine the impact of future demographic change on international living standards and the optimal rate of national saving. Notable features of the model include: an outward looking model of utility, a premium in the interest rate for capital importing regions, an exchange rate expressed as the relative price of traded and non-traded goods, and a vintage model of production. The world economy is divided into nine regions consisting of the eight regions in the United Nations long run demographic projections (1998 Revision) plus Japan as a separate region. The model is simulated for the low, medium and high fertility scenarios as projected for all regions by the United Nations. The model suggests that there will be a flow of international capital from the ageing regions to the younger regions; and that the world interest rate will fall. The lower world interest rate will cause a loss in living standards for ageing regions, the lenders, and a gain for the younger regions, borrowers. Lower fertility leads to greater downward movement in the world interest rate, thereby increasing the loss to ageing regions and the gain to younger regions of demographic change. The impact on living standards of alternative fertility rates is dominated by the dependency effect, with the capital widening and capital intensity effects playing minor roles. The real exchange rate response to demographic change turns out to be small in this model, particularly for the developing regions.
\end{abstract}




\section{The Effect of Fertility Rates on International Living Standards and Saving in a World Model with Flexible Real Exchange Rates}

\section{Introduction}

There is currently, in OECD countries in particular, a vigorous debate about the macroeconomic impact of future demographic change. Public concern is widespread that future demographic change will imply lower living standards. This concern has led to pressure on policy makers in high income countries to attempt by policy change to increase the fertility rate. However, the theoretical and empirical evidence is ambiguous. The transition to lower population growth caused by low fertility yields a short term dividend for living standards in the form of lower youth dependency and lower capital widening requirements. This dividend is offset later on by higher old age dependency. For a discussion along with simulation results see Weil, 1999; Elmendorf and Sheiner, 2000; and Guest and McDonald, 2002(c).

These models are, however, single region models. In a multi-region framework the effect on living standards depends on the effects of lower fertility rates on net international capital flows, through the effect on saving and investment flows, which in turn alters world interest rates. The effect of changing world interest rates on living standards differs for borrowing and lending regions. For borrowers the effect on income is positive while for lenders it is negative. Also, different rates of population ageing among regions will tend to alter real exchange rates which can in turn impact on relative living standards. Rapidly ageing regions, for example, will tend to experience appreciating real exchange rates to the extent that the increase in the relative price of labour in these countries tends to increase the price of non-traded relative to traded goods since non-traded goods are more labour intensive. 
This paper quantifies, by simulation, the impact of three scenarios of future demographic change, based on alternative fertility rates, on world interest rates and living standards. The three different fertility assumptions - low, medium and high implied by UN population projections for the $21^{\text {st }}$ century are used.

There are several classes of multi-regional macroeconomic models that can be used to simulate the macroeconomic implications of demographic change. The model in this paper is a two good, multi-regional Cass-Ramsey-Solow model. Although generations are not overlapping in this framework, heterogeneity of workers and consumers is captured by weighting for age-specific productivity and consumption needs, respectively. Single good versions of this class of models are the OECD model in Borsch-Supan (1996) and the two region open economy model in Cutler et al. (1990). A variation on this approach is the overlapping generations models of Turner et al. (1998) using the OECD's Minilink model, the models of the Ingenue Team (2001) and Fougere, M. and Merette, M. (1999), and the macroeconometric model of Masson and Tryon (1990). The distinction that we make here between traded and nontraded goods puts this model in the class of the multi-good, multi-region, general equilibrium models such as the G-cubed model (see, for example, McKibbin, W.J. and Nguyen, J., 2001), although the model here has less complexity than, for example, the G-cubed model.

\section{Demographic projections}

In this model, the world economy is divided into nine regions consisting of the eight regions in the United Nations (2000) long run demographic projections plus Japan as a separate region. The nine regions are: Africa, Asia (excluding China, India and Japan), China, Europe, India, Japan, Latin America, North America and Oceania. This is a 
larger number of regions than has been adopted in other models listed above. We choose for comparison the low, medium and high fertility scenarios in the United Nations projections (up to 2150). The medium scenario assumes that fertility in all major areas stabilizes at replacement level around 2050; the low scenario assumes that fertility is half a child lower than in the medium scenario; and the high scenario assumes that fertility is half a child higher than in the medium scenario.

For each of these population scenarios, employment projections by age and sex are calculated from the International Labour Organisation (ILO, 2001) database: Key Indicators of the Labour Market (KILM). These data provide labour force and population by age group and sex for each country in the world for the latest year typically 1999 or 2000 . From these data the aggregate labour force participation rates (LFPR) for each of the nine regions, by age group, are calculated. These age and sexspecific LFPRs are assumed to be the age-specific employment to population $(\mathrm{L} / \mathrm{N})$ ratios.

There is quite a wide variation in the $\mathrm{L} / \mathrm{N}$ ratios between regions. For example, for males and females combined the $\mathrm{L} / \mathrm{N}$ for $15-24$ year olds for Europe is 0.47 while it is 0.79 for China and 0.66 for North America. We assume that it is unlikely that such divergences will persist as economic development progresses. Hence employment projections for each region are calculated by assuming that the age-specific $\mathrm{L} / \mathrm{N}$ ratios (for both sexes) partially converge toward those of North America according to the following formula:

$$
(L / N)_{j, a}=(L / N)_{j-1, a}\left(\frac{(L / N)_{a}^{N A}}{(L / N)_{j-1, a}}\right)^{\sigma}
$$

where $j$ is the year from 2001 to $2150, N A$ is North America, $a$ is the age group, $\sigma$ is the convergence parameter set equal to 0.025 . 
Following Cutler et al. (1990) and Elmendorf and Sheiner (2000) the employment and population numbers are weighted to account for, respectively, agespecific differences in labour productivity and consumption needs. Labour productivity of middle-aged workers is higher than that of both younger and older workers and this is reflected in their relative wages. In the absence of reliable data for all regions on labour productivity by age, we adopt as an expediency the age-productivity relation in Miles (1999), where the productivity weight is a quadratic function of age: 0.05age 0.0006 age $^{2}$. Consumption needs also vary by age - in particular, education and medical expenses. To allow for this, we apply the consumption weights in Cutler et al (1990); that is 0.72 for $0-19$ year olds, 1.0 for $20-64$ year olds and 1.27 for over 64 year olds. Both productivity weights and consumption weights are non-gender specific.

The aggregate weighted $\mathrm{L} / \mathrm{N}$ ratio for each region is the support ratio (Cutler et al., 1990). A decrease in the support ratio implies a diminished capacity to meet a given level of consumption needs per capita. An increase in the support ratio implies the opposite. Chart 1 plots the support ratios for the nine regions for the medium fertility scenario which we refer to as the base case. The five regions with imminently declining support ratios are Japan, Europe, China, North America and Oceania. ${ }^{1}$ These regions will be referred to here as the ageing regions. The other four regions: Africa, Asia, India and Latin America, are younger in that their support ratios follow a humpshape, rising initially then declining. These regions will be described as the younger regions. This classification of regions is also valid for the low fertility and high fertility scenarios.

In order to ensure that the economy converges to a new steady state, the demographic projections described above are applied only for the period 2000 to 2100 , 
at which point the rate of growth of aggregate weighted employment is assumed to remain constant. This constant growth rate is also the rate at which aggregate weighted population is assumed to grow indefinitely.

\section{The model}

The important features of the model are described here. A full list of equations and variables are given in the Appendix. The method of solving the model is also described in the Appendix.

\subsection{Firms}

Output of traded and non-traded goods is produced according to vintage, CobbDouglas technology with constant returns to scale. While the vintage capital model, appropriately calibrated, yields the same long run solution as the homogeneous capital model (Solow, 1960), there can be differences in the short run response to shocks of, for example, a demographic nature (Guest and McDonald, 2001). For a generic comparison of vintage and homogenous capital models see Greenwood (1977). One practical reason for adopting a vintage rather than homogeneous capital model is that it obviates the need for adjustment costs in investment.

As in the two good model in Obstfeld and Rogoff, 1996, it is assumed that nontraded (N) goods cannot be capital goods, only consumer goods, which implies that the output of $\mathrm{N}$ goods is equal to the consumption of $\mathrm{N}$ goods. There are two reasons for this assumption: it simplifies the solution procedure (see Appendix) and it captures, to an approximation, the observation that consumption goods and services have a higher non-traded component than do traded goods.

\subsection{Consumers}

\footnotetext{
${ }^{1}$ The decline in the support ratio for Europe and for China does not commence until 2010 and 2005,
} 
Each region is populated by infinitely lived dynasties of people who differ only in that their consumption demands are age-specific. We consider the behaviour of a representative consumer whose age is the average age of the population, weighted by the population shares of each age group. For this consumer, we adopt the model of consumption in Obstfeld and Rogoff (1996), modified for a reference level of consumption in the intertemporal utility function (discussed below).

In this model, the consumer is faced with both an intratemporal and an intertemporal maximisation problem. The intratemporal optimisation problem is solved by optimally allocating a given value of consumption, measured as an index, between traded and non-traded goods. It is assumed that while all consumers are intratemporal optimisers not all consumers are intertemporal optimisers. Rather $30 \%$ of consumers are rule-of-thumb consumers, meaning that they always consume a fixed proportion of their income. This is a common assumption in applied economy-wide models; in the context of population ageing see, for example, the application of the MSG3 model in McKibbin and Nguyen, 2001 and the OECD's MINILINK model in Turner et a., 1998.

The consumers who optimise intertemporally maximise an outward-looking utility function, as in Carroll et al. (1997), where each consumer compares their consumption against the consumption of others in deriving their utility. Carroll et al. (1997) cite a range of evidence from the literature, both theoretical and empirical, in support of two alternative forms of what they call "comparison utility". ${ }^{2}$ From our point of view, perhaps the most compelling argument is that models of comparison

respectively. However, the initial rise in the support ratio is very small.

${ }^{2}$ One form of comparison utility is the "outward-looking" model that we adopt here. The other form is the "inward-looking" model in which consumers compare their consumption with their own past consumption rather than the consumption of others. Both forms of comparison utility generate a type of habit formation in consumption which implies the sort of persistence in consumption that we observe in 
utility generate persistence in the time series of consumption that matches the persistence found in the actual data.

\subsection{Assumptions about capital mobility and productivity growth}

We assume that capital is not perfectly mobile which is consistent with extensive evidence. For a discussion of the various explanations of imperfect capital mobility see Gordon and Bovenberg (1996); and for a survey of the evidence on the FeldsteinHorioka puzzle as an indicator of imperfect capital mobility see Coakley, Kulasi and Smith (1999). The most important explanation according to Gordon and Bovenberg (1996) is asymmetric information between investors of different countries. In particular, foreign investors know less about the economic prospects of another country than do the residents of that country. Gordon and Bovenberg develop a theoretical model, for which they find empirical support, in which the interest rate, $r$, in capital importing countries is higher than the world interest rate, $\bar{r}$. The latter is the rate received by lenders in capital exporting countries. The interest rate premium in capital importing countries is a function of the amount of capital imported. There is also evidence that countries - small countries in particular - face a risk premium that depends on their existing stock of foreign debt (see Juttner and Luedecke (1991) for the case of Australia). We allow for both of these mechanisms - asymmetric information and a risk premium - in determining the interest rate.

Steady state labour productivity growth is exogenous and constant at $1.5 \%$ per annum for all regions. This implies two things - first, that there is no influence of demographic change on technical progress and, second, that there is no convergence of labour productivity among the nine regions. On the effect of demographic change on technical progress both the theoretical and empirical evidence is ambiguous, as 
discussed by Cutler et al. (1990, p. 38). Consider slower population growth. On the one hand slower population growth makes innovation less profitable by reducing the gains from economies of scale through the spreading of fixed costs; and a smaller youth share of the population may reduce innovation through a loss of "dynamism"; also, in endogenous growth models such as that in Steinman et al. (1998) lower population growth results in less human capital accumulation and therefore a lower growth rate of labour productivity. On the other hand, there are several potential mechanisms through which slower population growth can boost labour productivity. Less urban congestion, for example, could enhance labour productivity growth. Also, slower labour force growth implies a higher relative price of labour and therefore greater incentive to innovate through capital investment. And the model in Fougere and Merrete (1998) shows that slower population growth will increase human capital formation, through tax effects, which could boost productivity growth if endogenous growth occurs through human capital formation. The empirical evidence on the effect of fertility on labour productivity is relatively scarce - see for example Galor et al. (1997), Ahituv (2001) and Hondroyiannis and Papapetrou (1999) - and somewhat conflicting. Hence the assumption here of zero net effect of demographic change on total factor productivity growth seems to be a reasonable starting point.

With respect to the zero convergence assumption, Barro and Salai-Martin (1995, p.26) report that the hypothesis of absolute convergence - where poor countries catch-up with rich countries in their GDP per capita, without allowing for any control variables - has received mixed empirical support. ${ }^{3}$ Nevertheless, most multi-regional macroeconomic models adopt some form of productivity convergence. Using the

view it does not matter whether we adopt the outward-looking model or the inward-looking model. ${ }^{3}$ The hypothesis of conditional convergence, which controls for various characteristics of economies, has received stronger empirical support. However, even the testing of this weaker hypothesis faces some 
OECDs multi-regional "Minilink" model, Turner et al (1998) assume slow convergence in the rates of technical progress of their five world regions, as distinct from convergence in their productivity levels. The Ingenue Team (2001) assume extremely slow convergence in levels of productivity - the gap between rich and poor countries appears to close by about $20 \%$ over 100 years. Dynamic intertemporal general equilibrium models, such as the G-Cubed Model, also typically incorporate some form of technology catch-up (McKibbin, 1999). In this paper, zero convergence in total factor productivity is assumed because, in our initial simulations, we found that all but a very small rate of convergence tended to swamp the effects of differences in fertility rates that we were attempting to isolate. As a result of this, and the uncertainty in the empirical literature about productivity convergence, we felt that zero convergence was a reasonable assumption for our purposes.

\section{The simulation method}

The solution procedure is to first calibrate an initial steady state which implies that both population and employment are initially growing at constant rates. The demographic projections are then introduced as unanticipated "shocks". Cutler et al. (1990) argue that "it is not obvious how best to model [demographic change] as a single shock" (p.23). The approach they and others typically adopt is to assume that the population has been stable at which point a demographic shock occurs so that employment and population follow the projections described above. Following the shock, it is assumed that consumers and firms know the future demographic structure and choose optimal consumption and investment levels accordingly. 
Once the initial steady state is defined for each region, the optimal path in response to the demographic shock is determined by finding the new initial value of the consumption index that leads to the steady state. Given the resulting paths for all nine regions of the world, the model is closed by ensuring that the world current account balance is zero. This is achieved by an iterative process as follows. An arbitrary initial path of the world interest rate is chosen over a very long horizon and, given this path, the optimal plan for each region is calculated so that the economy reaches a steady state. Then a new path of the world interest rate is chosen by adjusting the interest rate in each year in which the world current account balance is not equal to zero. This process is repeated until the world current account balance is equal to zero in each year.

\section{Saving, investment, net capital flows and the world rate of interest}

Figure 2 shows the impact of the future patterns of demographic change on the world rate of interest. Under all fertility scenarios the world interest rate falls, following a small adjustment upwards immediately following the shock.

The demographic shock initially increases optimal saving slightly in the ageing regions (as identified in Figure 1) because their consumption possibilities are lower as a result of ageing. It is therefore optimal to smooth consumption by making an immediate downward adjustment to consumption starting from a steady state. ${ }^{4}$ After a brief initial period, saving steadily declines for the ageing regions, reflecting their declining capital requirements which is evident in the investment series in Figure 3. The younger regions initially reduce optimal saving because their consumption possibilities are higher as a result of their populations initially becoming younger for a 
period of some years, as indicated by their rising support ratios. After this initial adjustment saving rises for these regions, reflecting their growing capital requirements.

The net effect of these saving and investment patterns is a small initial increase in the world interest rate following the ageing shock followed by a decline by about one percentage point from maximum to minimum. For base case demographics the world interest rate remains below its current level from 2010 onwards.

For most of the next century - from 2020 onwards - the lower are fertility rates around the world the lower is the world interest rate (Figure 2). A lower fertility scenario amounts to a bigger ageing shock which magnifies the response of world saving and investment, resulting in a larger initial rise and larger subsequent fall in the world interest rate. A higher world fertility scenario has converse effects - a smaller demographic shock resulting in a smaller fall in the world interest rate.

Alternative world fertility scenarios have different effects on savings of ageing regions compared with younger regions. For illustration, Figure 3 compares the effect of the demographic shock caused by the medium (base) and low fertility scenarios on saving, investment and the current account balance. For the younger regions, the effect of low fertility on saving is muted compared with the effect on ageing regions. The reason for this can be seen by considering the income and substitution effects of a lower interest rate. For ageing regions, who are lenders, lower interest rates reduce saving through substitution and through income. But younger regions are debtors, borrowing to finance their higher consumption possibilities. For debtors, lower interest rates have offsetting income and substitution effects on saving. The substitution effect tends to reduce saving while the income effect tends to increase it. The net result is a small decrease in saving relative to that for ageing regions.

\footnotetext{
${ }^{4}$ Note that in a model with imperfect capital mobility it is not optimal to adjust immediately to the new
} 
Current account surpluses of the ageing regions are matched by current account deficits of the younger regions, implying the export of capital from the former to the latter. ${ }^{5}$ Lower fertility rates impact only very slightly on the size of these capital flows - saving is lower but so is investment.

\section{Living standards}

Living standards are defined as aggregate consumption per equivalent person, $\mathrm{C} / \mathrm{P}$. The impact on living standards of a demographic shock is the net result of three effects: the dependency effect, the capital widening effect and a labour productivity effect, see Elmendorf and Sheiner $(2000)^{6}$.

Higher (lower) overall dependency (the combination of youth and old age dependency) implies fewer (more) workers per person, which reduces (increases) consumption possibilities. The capital widening effect refers to the impact of a change in the rate of growth of employment on the level of investment needed to maintain a given capital-labour ratio. Lower (higher) employment growth increases (decreases) consumption possibilities. The labour productivity effect refers to the temporary change in labour productivity resulting from the temporary change in capital labour ratios as a result of a demographic shock. In a two good model such as this, average labour productivity is also affected by shifting of labour between sectors of unequal labour productivity. Since the T sector in this model has higher labour productivity than the $\mathrm{N}$ sector, any relative expansion or contraction of the $\mathrm{T}$ sector has an

\footnotetext{
steady state level of consumption because the interest rate varies along the optimal path and this alters the path of consumption.

${ }^{5}$ The description of ageing regions as creditors and younger regions as debtors refers to the short term response to the ageing shock, typically for the first two decades at least. Beyond that, the pattern is reversed in some cases. Also, Europe is neither a significant creditor or large debtor in the short term. This is consistent with the pattern of its support ratio (Figure 1) which shows a small rise initially before it declines.

${ }^{6}$ Elmendorf and Sheiner refer to a capital intensity effect which we call a labour productivity effect because it is perhaps more descriptive for this model (see discussion below).
} 
expansionary or contractionary effect on average labour productivity. ${ }^{7}$ The assumption here that $\mathrm{N}$ sector output consists entirely of consumption goods - that is, $\mathrm{Y}_{\mathrm{N}}=\mathrm{C}_{\mathrm{N}}$ means that any adjustment to the aggregate consumption to output ratio must fall on the $\mathrm{T}$ sector. In the case of Japan for example, the aggregate consumption to output ratio rises following the shock and this draws labour from the higher productivity $\mathrm{T}$ sector to the low productivity $\mathrm{N}$ sector. Hence average labour productivity falls. For Africa however, the process works in reverse; the aggregate consumption to output ratio falls therefore labour is released into the $\mathrm{T}$ sector which raises average labour productivity. The implication is that the low fertility scenario results in a bigger fall in average labour productivity than does the base scenario for ageing regions like Japan; and a bigger rise in average labour productivity than under the base case for younger regions like Africa.

Figure 4a illustrates the effects of the demographic shock on living standards for both a representative ageing/creditor region (Japan) and a representative younger/debtor region (Africa) under base, low and high fertility scenarios. ${ }^{8}$ It can be seen that the demographic shock has different impacts on living standards for the ageing regions compared with the younger regions. The shock reduces living standards in the ageing regions and raises living standards in the younger regions. This is due to two effects. First, because ageing regions face an imminent decline in their support ratios (Figure 1) their living standards fall, relative to the no demographic change outcome. Younger regions, however, face rising support ratios for an initial period (Figure 1). This allows them to enjoy living standards that are higher than they would be if there were no demographic change. Second, the reduction in the world rate of

\footnotetext{
${ }^{7}$ The strong assumption: $\mathrm{Y}_{\mathrm{N}}=\mathrm{C}_{\mathrm{N}}$ is not necessary for this a result to apply. It only requires that $(\mathrm{C} / \mathrm{Y})_{\mathrm{N}}>(\mathrm{C} / \mathrm{Y})_{\mathrm{T}}$ and that $(\mathrm{K} / \mathrm{L})_{\mathrm{T}}>(\mathrm{K} / \mathrm{L})_{\mathrm{N}}$.
} 
interest reduces incomes in the ageing regions because they are creditors and increases income in the younger regions, who are debtors. These effects of the demographic shock - higher living standards for ageing regions and lower living standards for younger regions - apply for all fertility scenarios.

A lower fertility shock tends to improve living standards in the near term and reduce them later on (see Figures $4 \mathrm{a}$ and $4 \mathrm{~b}$ ). Lower fertility has offsetting effects on consumption possibilities. There are consumption dividends from lower youth dependency and lower capital widening requirements which are offset by higher old age dependency later on. How the net effect of these is smoothed out depends on the path of the interest rate. Lower fertility rates put downward pressure on interest rates. This creates an intertemporal substitution effect, which is to bring consumption forward. The result is the pattern in Figure $4 \mathrm{~b}$ showing higher consumption for an initial period under lower fertility, but lower consumption later on.

Figures $4 \mathrm{a}$ and $4 \mathrm{~b}$ show only two regions in order to clearly illustrate the patterns in graphical form. For all regions, the effects of lower and higher fertility relative to medium fertility are summarised in Table 2 . As can be seen from this table, it is generally the case that the initial gain from lower fertility is smaller for the ageing regions, and is more short-lived, than for the younger regions. The reason is the different income effects, for ageing/lending regions and younger/borrowing regions, of the change in interest rates brought by lower fertility.

\footnotetext{
${ }^{8}$ Japan and Africa are extreme examples of ageing and younger regions, respectively. They are chosen to emphasise the contrast between these two types of regions. They are representative in that the other regions in their group are similar to them.
} 


\begin{tabular}{|c|c|c|c|c|c|c|c|c|c|}
\hline \multicolumn{10}{|c|}{$\begin{array}{l}\text { Table } 2 \text { Effects of low and high fertility on living standards } \\
\text { LOW FERTILITY } \\
\text { change in consumption per equivalent person relative to medium fertility* }\end{array}$} \\
\hline & \multicolumn{5}{|c|}{ ageing regions } & \multicolumn{4}{|c|}{$\begin{array}{l}\text { younger regions } \\
\end{array}$} \\
\hline & Nth Am & Jap & China & Europe & Oceania & India & Latin Am & Africa & Asia \\
\hline 2010 & 1.3 & 0.5 & 1.6 & 1.0 & 1.8 & 2.3 & 2.1 & 1.7 & 2.2 \\
\hline 2020 & 1.6 & 1.0 & 2.2 & 1.4 & 2.2 & 3.2 & 2.8 & 2.6 & 2.8 \\
\hline 2030 & 0.9 & 1.0 & 1.7 & 1.1 & 1.6 & 2.9 & 2.6 & 3.3 & 2.7 \\
\hline 2040 & -0.6 & 0.3 & 0.4 & 0.0 & 0.3 & 1.8 & 1.5 & 3.1 & 1.8 \\
\hline 2050 & -2.9 & -1.5 & -1.8 & -2.1 & -1.9 & -0.7 & -0.8 & 1.8 & -0.3 \\
\hline \multirow{4}{*}{2100} & -14.8 & -9.7 & -7.8 & -10.8 & -7.8 & -7.7 & -7.2 & -5.9 & -7.0 \\
\hline & $\begin{array}{r}{ }^{*} \text { The above } \\
\text { from low fe } \\
\% \text { c }\end{array}$ & $\begin{array}{l}\text { anel shows } \\
\text { ility than do } y \\
\text { ange in cc }\end{array}$ & $\begin{array}{l}\text { at, at any gi } \\
\text { unger regior } \\
\text { isumptio }\end{array}$ & $\begin{array}{l}\text { t time, ageir } \\
\text { GH FERT } \\
\text { per equiv }\end{array}$ & $\begin{array}{l}\text { gions gene } \\
Y \\
\text { nt perso }\end{array}$ & ally face sm & gains and/c & or bigger loss & \\
\hline & \multicolumn{5}{|c|}{$\begin{array}{l}\text { ageing regions } \\
\end{array}$} & \multicolumn{4}{|c|}{ younger regions } \\
\hline & Nth Am & Jap & China & Europe & Oceania & India & Latin Am & Africa & Asia \\
\hline 2010 & -1.8 & -0.6 & -1.1 & -1.6 & -0.8 & -2.2 & -2.2 & -1.7 & -2.0 \\
\hline 2020 & -1.9 & -1.0 & -1.8 & -1.7 & -1.0 & -3.0 & -2.7 & -2.5 & -2.7 \\
\hline 2030 & -1.0 & -0.9 & -1.6 & -1.0 & -0.9 & -2.8 & -2.5 & -2.9 & -2.6 \\
\hline 2040 & -0.1 & -0.4 & -0.9 & 0.5 & -1.1 & -2.2 & -1.9 & -2.9 & -2.1 \\
\hline 2050 & 1.1 & 1.1 & 0.3 & 2.6 & -0.9 & -0.9 & -0.5 & -2.4 & -0.9 \\
\hline 2100 & 7.2 & 5.2 & 3.8 & 5.3 & 2.8 & 3.4 & 3.4 & 2.4 & 3.4 \\
\hline & $\begin{array}{l}\text { *The above } \\
\text { from high } \mathrm{f}\end{array}$ & $\begin{array}{l}\text { anel shows } \\
\text { ility than do }\end{array}$ & $\begin{array}{l}\text { at, at any gi } \\
\text { unger regic }\end{array}$ & time, age & IOns get & ally face bi & ains and $/ o$ & smaller los & \\
\hline
\end{tabular}

We now decompose the total effect on living standards into the three

component effects according to the following identity:

$\frac{C}{P}=\frac{C}{Y} \frac{Y}{L} \frac{L}{P}$

which in per person or per worker units is

$c=\frac{c}{\alpha y} y \alpha$

We focus on the case of lower fertility for illustration - the results for higher fertility are the converse of those for lower fertility. The dependency effect of lower fertility describes the lower consumption possibilities that result from there being fewer workers relative to consumers, which is the case once the short term reduction in youth dependency is offset by the rise in old age dependency. The dependency effect is the effect on consumption possibilities of a lower value of $\mathrm{L} / \mathrm{P}=\alpha$ and is therefore approximated $^{9}$ by, according to $(2),(c / \alpha)^{\text {base }}\left[\alpha^{\text {low }}-\alpha^{\text {base }}\right]$. This gives the net effect of a reduction in youth dependency and an increase in old age dependency. The capital 
widening effect refers to the lower capital requirements of a more slowly growing labour force, which increases consumption possibilities. A lower investment share of output allows a higher consumption share $(\mathrm{C} / \mathrm{Y})$, other things equal. Therefore, the capital widening effect is given by $(y \alpha)^{\text {base }}\left[(c /(y \alpha))^{\text {low }}-(c /(y \alpha))^{\text {base }}\right]$. The labour productivity effect refers to changes in $\mathrm{Y} / \mathrm{L}=y$ holding all else constant and is given by $(c / y)^{\text {base }}\left[y^{\text {low }}-y^{\text {base }}\right]$.

The three effects of lower world fertility rates are plotted in Figure 5 for the representative ageing region (Japan) and the representative younger region (Africa). The dependency effect accounts for virtually the entire effect on living standards, with the capital widening effect and labour productivity effects almost cancelling each other out.

\section{The role of the real exchange rate}

The distinction between traded and non-traded goods adds quite a degree of complexity to the model. The motivation for this was the possibility that different rates of population ageing would alter the relative price of non-traded goods across regions. The idea is that shortages of labour require imply higher real wages relative to the cost of capital, which increases the relative prices of non-traded goods since they are relatively labour intensive. Hence the rapidly ageing regions would face higher relative prices of non-traded goods and therefore higher real exchange rates, which could in turn impact on living standards. Simulations revealed however that the real exchange rate response to demographic shifts is quite small, especially for the developing regions. See Figure 6.

\footnotetext{
${ }^{9}$ Ignoring second order terms.
} 
The exchange rate is determined by the interest rate which does not respond much to the demographic changes simulated here. The maximum change in the interest rate from peak to trough is about one percentage point. One reason for the modest response of the interest rate is the equilibrating forces that operate when interest rates change. Consider younger regions (Africa, Latin America and Asia) for whom population ageing is relatively distant. They face strong demand for capital relative to saving and therefore their foreign debt rises which raises their interest rates and hence lowers the relative price of labour. (At the same time their relative abundance of labour increases which further lowers the relative price of labour.) The higher return to saving induces higher optimal saving and lower demand for capital which offsets the first round effect on debt and interest rates. The reverse applies for regions facing current or imminent population ageing. They face weak demand for capital relative to saving which reduces their foreign liabilities and hence lowers their interest rates and hence raises their relative price of labour. They face further pressure on the relative price of labour from the shortage of working age people. The resulting fall in interest rates encourages current consumption rather than saving which helps to reverse the process of falling interest rates. These equilibrating effects mitigate the interest rate response to demographic change.

The magnitude of the response of the real exchange rate also depends on the difference in capital labour ratios between the two sectors (see Appendix B for derivation). In general, the size of the gap between the capital labour ratios for the traded and non-traded sectors determines the magnitude of the effect of a given demographic change on the real exchange rate. Hence if there is very little difference in the capital labour ratios then a proportional change in aggregate employment (via a demographic shock) will cause very little proportional change in the exchange rate. 
This is what happens for developing regions, especially Africa, India and Latin America. They have very low overall capital labour ratios which means that the absolute difference in those ratios for the two sectors is small. Hence the real exchange rate response to demographic change is smaller for those regions. This effect, together with the small response in the interest rate described above, means that the absolute impact on the exchange rate is particularly small for developing regions.

\section{Conclusion}

From the simulations in this paper, four major conclusions stand out. First, under all three of the UN demographic scenarios - that is, low, medium and high fertility, the ageing regions will tend to be lenders and the young regions will tend to borrow. This pattern reflects the greater investment opportunities in the younger regions, due to faster employment growth. These investment opportunities will attract international capital flows. Second, under all demographic scenarios world interest rates can be expected to be lower for most of the next century. This is because, over this period, demographic change will cause greater downward pressure on world investment than on world saving. Third, demographic change, under all fertility scenarios, will have an adverse effect on living standards in the ageing regions and a beneficial effect in the young regions. The increased dependency in the ageing regions contrasted with a period of decreased dependency in the younger regions is one reason for this. However there is a second reason. Because ageing regions are lenders and therefore creditors, lower interest rates will cause a loss in income and thus living standards. For young regions, which are the borrowers and therefore debtors, low interest rates will improve income and living standards. Fourth, the real exchange rate responses to the demographic changes simulated here are relatively small and therefore will not play a 
significant role in the effect on living standards. This is particularly so for the developing countries because their capital labour ratios are lower than those of the developed regions. 


\section{Appendix A}

This Appendix describes the analytics of the model and the solution procedure.

Let $Y_{T}$ and $Y_{N}$ be output of traded (T) and non-tradable (N) goods, respectively. Let $V_{T}$ and $V_{N}$ be the number of vintages of capital employed in producing tradable and non-tradable goods, respectively ${ }^{10}$. Assume that output is produced according to a vintage production function with Cobb-Douglas technology:

$$
\begin{aligned}
Y_{T, t} & =\sum_{k=0}^{V_{T}-1}\left[\left(1-\delta_{T}\right)^{k-1} A_{T, t-k}\left(I_{T, t-k}\right)^{\gamma}\left[L_{T, t-k-1}\left(l_{T, t-k}+\delta_{T}\right)\right]^{1-\gamma}\right] \\
Y_{N, t} & =\sum_{k=0}^{V_{N}-1}\left[\left(1-\delta_{N}\right)^{k-1} A_{N, t-k}\left(I_{N, t-k}\right)^{\gamma}\left[L_{N, t-k-1}\left(l_{N, t-k}+\delta_{N}\right)\right]^{1-\gamma}\right]
\end{aligned}
$$

which can be approximated by

$$
\begin{aligned}
& Y_{T}=Y_{T,-1}\left(1-\delta_{T}\right)+A_{T} I_{T}^{\gamma}\left(L_{T,-1}\left(l_{T}+\delta_{T}\right)\right)^{1-\gamma} \\
& Y_{N}=Y_{N,-1}\left(1-\delta_{N}\right)+A_{N} I_{N}^{\gamma}\left(L_{N,-1}\left(l_{N}+\delta_{N}\right)\right)^{1-\gamma}
\end{aligned}
$$

which, in turn, can be expressed in intensive form where $y$ is output in efficiency units per equivalent worker.

$$
\begin{aligned}
& y_{T}=y_{T,-1} \frac{\left(1-\delta_{T}\right)}{\left(1+x_{T}\right)}+i^{\gamma}\left[\frac{l+\delta}{1+l}\right]_{T}^{1-\gamma} \\
& y_{N}=y_{N,-1} \frac{\left(1-\delta_{N}\right)}{\left(1+x_{N}\right)}+i^{\gamma}\left[\frac{l+\delta}{1+l}\right]_{N}^{1-\gamma}
\end{aligned}
$$

Let $q_{T}$ and $q_{N}$ be the effective labour available to work on new capital. It can be shown that for the $\mathrm{T}$ and $\mathrm{N}$ sectors $q=\frac{i(1+l)}{l+\delta}$. To see this, note that $i=\frac{I}{A L}$ and therefore

\footnotetext{
${ }^{10}$ We follow the assumption in Obstfeld and Rogoff (1996) that only tradable goods can be transformed into capital. They describe this assumption as "inessential but helpful" (p.204). In our version of their model this assumption allows an analytic solution for $\mathrm{l}_{\mathrm{N}}$ and $\mathrm{l}_{\mathrm{T}}$; otherwise numerical methods would be required.
} 
$i(1+l)=\frac{I(1+l)}{A L_{-1}(1+l)}=\frac{I}{A L_{-1}}$. Therefore $q=\frac{I}{A L_{-1}(l+\delta)}=\frac{i(1+l)}{l+\delta}$ is the ratio of new

capital, $I$, to effective labour available to work on new capital, $A L_{-1}(l+\delta)$. The latter consists of the share, $l$, of the increase in aggregate employment and the share, $\delta$, of aggregate employment that has been from capital that has been scrapped.

Investment in each of the two sectors is determined by the condition that the marginal product of capital is equal to the user cost of capital, $r+\delta$. Therefore

$q_{T}=\left(\frac{\gamma}{r+\delta_{T}}\right)^{1 / 1-\gamma}$

$q_{N}=\left(\frac{e \gamma}{r+\delta_{N}}\right)^{1 / 1-\gamma}$

The real wage, $w$, is equal to the marginal product of labour in each sector. That is,

$A_{T}^{1 / 1-\gamma}(1-\gamma)\left(q_{T}\right)^{\gamma}=w$

$e\left[A_{N}^{1 / 1-\gamma}(1-\gamma)\left(q_{N}\right)^{\gamma}\right]=w$

The four equations (A7) to (A10) can be solved for the four endogenous variables $q_{T}, q_{N}, w$ and $e$. However, in order to determine $i_{T}$ and $i_{N}$ from $q_{T}$ and $q_{N}$ it is necessary to allocate the exogenously given growth in aggregate employment between $l_{T}$ and $l_{N}$. This is done by first assuming that $\mathrm{N}$ goods cannot be capital goods, only consumer goods. This implies that the output of $\mathrm{N}$ goods is equal to the consumption of $\mathrm{N}$ goods (following the assumption in Obstfeld and Rogoff, 1996). To explain how this allows us to separate out $l_{T}$ and $l_{N}$ we begin by describing the model of consumption.

The consumer's intratemporal maximization problem. 
Define an index of total consumption for the representative consumer (see Table 1 for the full list of variables) at time $t$ :

$c_{t}=\left[\mu_{t}^{1 / \psi} c_{T, t}^{\psi-1} / \psi+\left(1-\mu_{t}\right)^{1 / \psi} c_{N, t}^{\psi-1} / \psi\right]^{\psi / \psi-1}$

$\mu_{t}$ is time varying because the representative consumer's relative preferences for traded and non-traded goods vary with age. This reflects the observation that preferences for medical and health services, which are essentially non-traded goods, are agedependent. In particular, we would expect that dependents, who are predominantly the young and old, have a higher demand for non-traded relative to tradable goods than do working age people. A simple way to accommodate this is to assume that age-based variation in consumption demands reflects entirely variation in demand for nontradable relative to tradable goods. This implies that $\mu$ for the representative consumer varies over time in proportion to variation in average consumption demands, defined as $\left(\frac{N}{P}\right)_{t}$. Therefore, $\mu_{t}=\mu_{0}\left(\frac{N}{P}\right)_{t}$.

Total expenditure on $\mathrm{c}_{\mathrm{T}}$ and $\mathrm{c}_{\mathrm{N}}$, measured in units of $\mathrm{T}$ goods is, dropping time subscripts

$E \equiv c_{T}+e c_{N}$

In each period the consumer maximizes (A11) subject to (A12) yielding

$\frac{\mu c_{N}}{(1-\mu) c_{T}}=e^{-\psi}$

Combining (11) and (12) yields

$c_{T}=\frac{\mu E}{\mu+(1-\mu) e^{1-\psi}} \quad ;$ and $\quad c_{N}=\frac{p^{-\psi}(1-\mu) E}{\mu+(1-\mu) e^{1-\psi}}$

Let $P^{C}$ be the price, in T goods, of a unit of the consumption index and it is defined as the minimum $E$ such that $c=1$. Using this and substituting (A14) into (A12) yields 
$P^{C}=\left[\mu+(1-\mu) e^{1-\psi}\right]^{1 / 1-\psi}$

Given (A14), (A15) and the definition that $\mathrm{E}=\mathrm{cP}^{\mathrm{C}}$, gives

$c_{T}=\mu\left(\frac{1}{P^{C}}\right)^{-\psi} c \quad ; \quad$ and $\quad c_{N}=(1-\mu)\left(\frac{e}{P^{C}}\right)^{-\psi} c$

This solves the intratemporal maximization problem for the representative consumer.

The consumer's intertemporal maximization problem.

It is assumed that a proportion, $(1-\xi)$, of consumers are intertemporal optimisers and $\xi$ are rule-of-thumb consumers who consume a constant proportion of their income.

The utility that consumers derive from a given amount of consumption differs according to their consumption demands. The representative consumer maximizes the following intertemporal utility function:

$U=\sum_{t=1}^{\infty}\left[\frac{c^{o p t} / s}{z^{\omega}}\right]_{t}^{1-\beta} \frac{(1+\theta)^{1-t}}{1-\beta} \quad \quad \mathrm{j}=1, . ., \mathrm{h}$

where $z$ is a reference stock of consumption and $s$ is the weighted average of the agespecific consumption weights of all consumers at time $t$. The age-specific consumption weights are: 0.72 for people under $20,1.0$ for people from 20-64 and 1.27 for those over 64 .

In (A17) $\mathrm{c}^{\text {opt }}$ denotes the consumption of intertemporally optimising consumers. Consumers are assumed to be outward looking in the sense that their reference stock of consumption, $z$, is a function of the average consumption of all consumers across all age groups rather than a function of their own consumption. The parameter $\omega$ indexes the importance of the reference stock of consumption. Here we set $\omega=1$ and define $z_{t}=c^{o p t}{ }_{t-1}$ which is equal to the average consumption of all optimising consumers in period $t-1$.

The first order condition for intertemporally optimising consumers is 


$$
\frac{\partial V_{i}}{\partial c^{o p t}} \int_{t} \frac{\partial V_{i}}{\partial c^{o p t}{ }_{t+1}}=\left(1+r_{t+1}^{C}\right)=\left(1+r_{t+1}\right) \frac{P_{t}^{C}}{P_{t+1}^{C}}
$$

where $r^{C}$ is the own rate of interest on the consumption index, $c ;{ }^{11}$ and $r$ is the rate of interest on tradables. Bonds are indexed to tradables so that $B$ bonds are a claim on $r B$ tradables per period (Obstfeld and Rogoff, 1996, p.229). Note that in the steady state, $P^{C}=P^{C}{ }_{t+l}$ and therefore $r^{C}{ }_{t+l}=r_{t+l}$.

Reflecting the effects of both asymmetric information in foreign investment and a risk premium, the interest rate is determined by the following simple linear function $^{12}$ :

$$
r=\bar{r}+\lambda_{1}\left(d-d_{-1}\right)+\lambda_{2} d
$$

where $\lambda_{2}=0.01$ and if $\left(d-d_{-1}\right)>0$ then $\lambda_{1}=0.1$, otherwise $\lambda_{1}=0$. These parameter values are broadly consistent with the empirical evidence in Gordon and Bovenberg (1996) for capital importing countries. It implies that a region with a current account deficit of $5 \%$ of GDP and debt equal to $50 \%$ of GDP has an equilibrium interest rate that is $1 \%$ above the world interest rate. Simulations showed that the size of $\lambda_{1}$ and $\lambda_{2}$ have some effect on the optimal paths of living standards for a given demographic scenario but have almost no effect on the impact that alternative fertility scenarios have on optimal paths of living standards.

The solution to (A18) given (A19), yields:

\footnotetext{
${ }^{11}$ The intuition for the difference between $\mathrm{r}$ and $\mathrm{r}^{\mathrm{C}}$ is as follows. $\mathrm{P}^{\mathrm{C}}$ is a monotonic increasing function of $\mathrm{p}$; and $\mathrm{e}=\mathrm{P}^{\mathrm{N}} / \mathrm{P}^{\mathrm{T}}$. Hence if $\mathrm{P}$ falls over time (i.e. $\mathrm{P}^{\mathrm{C}} / \mathrm{P}^{\mathrm{C}}{ }_{\mathrm{t}+1}$ is rising), then $\mathrm{T}$ goods are becoming more expensive relative to $\mathrm{N}$ goods. Therefore a dollar of expenditure buys fewer traded goods relative to units of the consumption index, than before. Hence the own interest rate on $\mathrm{T}$ goods has to rise to equal a given own interest rate on the consumption index.

${ }^{12}$ For capital importing regions, while the interest rate, $r$, represents the equilibrium interest rate which is both the return on saving and the cost of capital (less depreciation), it is not equal to the rate that is paid on overseas borrowing. The latter is equal to $\bar{r}+\lambda_{2} d$ which (for those regions) is less than $r$.
} 
$\frac{\dot{c}^{o p t}}{c^{o p t}}=\frac{1}{\beta}\left(\frac{\partial r}{\partial d} d+r-\dot{P}^{C}-\theta+(\beta-1)\left(\frac{\dot{z}}{z}+p-n\right)\right)-g$

The consumers who, as a rule-of-thumb, consume a fixed proportion of their income, have the same consumption as the optimising consumers in the initial steady state but hold that level fixed as a proportion of their income. Hence the ageing shock only affects their consumption only insofar as it alters their level of income, which is the same for all consumers. The consumption of rule-of-thumb consumers is denoted, $\mathrm{c}^{\text {rot }}$; note that $\mathrm{c}=\xi \mathrm{c}^{\mathrm{rot}}+(1-\xi) \mathrm{c}^{\mathrm{opt}}$

The standard national accounting identity gives the equation of motion for debt.

$\dot{d}=(r(d)-x) d+\frac{c}{\alpha}+i_{T}+e i_{N}-y_{T}-p y_{N}$

The steady state implies that $\dot{d}=0$ and $\dot{c}=0$ which yields the following steady state equations:

$c=\alpha\left(y_{T}+p y_{N}-i_{T}-e i_{N}-(r(d)-x) d\right)$

$\theta=r-\beta g$

\section{$\underline{\text { Calibration and solution }}$}

The production function is calibrated such that the capital intensity the T sector is higher than in the $\mathrm{N}$ sector by assumption. In particular the capital output ratio in the T sector, $(\mathrm{k} / \mathrm{y})_{\mathrm{T}}$, is assumed to be 1.25 times the value of $\mathrm{k} / \mathrm{y}$ for both sectors combined. This implies that for the $\mathrm{T}$ sector, the depreciation rate is lower and/or the capital elasticity of output is higher than in the $\mathrm{N}$ sector. We assume that the two sectors have the same capital output elasticities but different rates of depreciation. In 
particular, given the first order condition for investment and the condition that output and capital are in an initial steady state, $\delta_{T, N}=\gamma\left(\frac{k_{0}}{y_{0}}\right)_{T, N}^{-1}-r$.

The initial exogenously given employment level is allocated between the $\mathrm{T}$ and $\mathrm{N}$ sectors as follows. We follow the simplifying assumption in Obsfeld and Rogoff (1996) that N goods cannot be capital goods - they can only be consumption goods. This implies that output in the $\mathrm{N}$ sector is determined by consumption in the $\mathrm{N}$ sector; that is, $\mathrm{Y}_{\mathrm{N}}=\mathrm{C}_{\mathrm{N}}$. In turn, $\mathrm{C}_{\mathrm{N}}$ is given by (A14), where the initial steady state value of $\mathrm{C}$ is determined by (A22). Hence given the parameter, $\mu$, the shares of $Y_{N}$ and $Y_{T}$ in initial GDP (exogenously given) can determined endogenously. However, given we know more about the actual shares of $\mathrm{N}$ and $\mathrm{T}$ goods in output from available data than we do about the value of $\mu$ in the intratemporal utility function, it is more sensible to calibrate $\mu$, given exogenous values for the output shares of $\mathrm{T}$ and $\mathrm{N}$ goods.

Proceeding in this way, let initial output in the T sector be an exogenously given proportion, $b$, of initial aggregate GDP. This implies that $\frac{L_{0, N}}{L_{0, T}}=\frac{y_{0, T}}{y_{0, N}} \frac{(1-b)}{b}$ where $y_{0}$ is given for both sectors by assuming an initial steady state in which $y_{l}=y_{0}$ and $l=l_{N}=l_{T}$. Given aggregate initial $\mathrm{L}$, then $\mathrm{L}_{0, \mathrm{~N}}$ and $\mathrm{L}_{0, \mathrm{~T}}$ can be determined, and hence $\mathrm{Y}_{\mathrm{N}}$. The value of $\mu$ is then solved for by setting $\mathrm{Y}_{\mathrm{N}}=\mathrm{C}_{\mathrm{N}}$. Hence it is necessary to set exogenously either of the parameters $\mu$ or $b$, from which the other is determined.

In order to calculate output in each sector over time it is necessary to allocate the growth rate of aggregate employment between the T and $\mathrm{N}$ sectors: $l_{T}$ and $l_{N}$. This is done by noting that $\mathrm{Y}_{\mathrm{N}}=\mathrm{C}_{\mathrm{N}}$ at each point in time and using (A16) and (A20) to determine $\mathrm{C}_{\mathrm{N}}$. The following analytic solution for $l_{N}$ is derived: 
$l_{N}=\left[\frac{C_{N}-Y_{N,-1}\left(1-\delta_{N}\right)}{A_{N}^{1 / 1-\gamma} L_{N,-1} q_{N}^{\gamma}}\right]-\delta_{N}$

The remaining base case parameter values adopted in the model are : $\beta=2.0$, $\alpha=0.3, r$ in a steady state $=0.05, g=0.015,{ }^{13} \xi=0.3, \psi=1.0$.

\footnotetext{
${ }^{13}$ A steady state rate of labour productivity growth of $1.5 \%$ implies a rate of total factor productivity growth of approximately $1 \%$ given the elasticity in the production function.
} 
Table 1 Symbols for variables and parameters used in the model

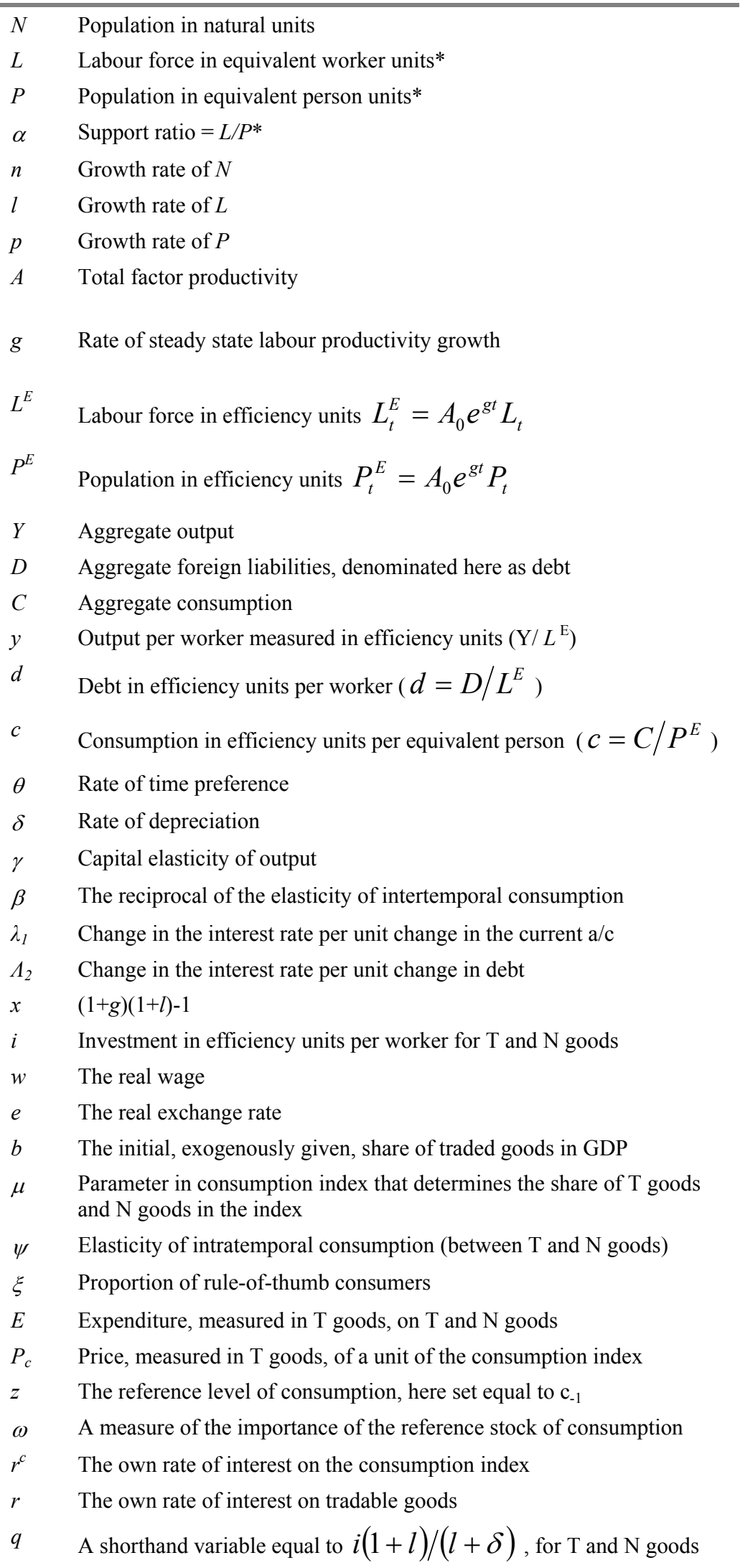




\section{Appendix B}

This Appendix derives the result, given in the text, that the exchange rate response depends on the absolute difference in the capital labour ratios between the two sectors.

Solving (A7) to $\mathrm{A}(10)$ above for the exchange rate, $e$, gives:

$e=\left(\frac{q_{T}}{q_{N}}\right)^{\gamma}$

Let $l_{T}^{*}=\left[A L_{-1}(l+\delta)\right]_{T}$ and $l_{N}^{*}=\left[A L_{-1}(l+\delta)\right]_{N}$ which is the total effective

labour available to work on new capital in the $\mathrm{T}$ and $\mathrm{N}$ sectors respectively.

Then, from the definition of $q$ given in Appendix A, $q_{T}=\left(\frac{I}{l^{*}}\right)_{T}$ and $q_{N}=\left(\frac{I}{l^{*}}\right)_{N}$. Let the total employment available to work on new capital be denoted by $l^{*}$; that is $l^{*}=l_{T}^{*}+l_{N}^{*}$. Substituting $q_{T}$ and $q_{N}$ into (B1) gives

$$
\begin{aligned}
\ln e & =\gamma\left(\ln \left(\frac{I}{l^{*}}\right)_{T}-\ln \left(\frac{I}{l^{*}}\right)_{N}\right) \\
& =\gamma\left(\ln I_{T}-\ln l_{T}^{*}-\ln I_{N}+\ln l_{N}^{*}\right)
\end{aligned}
$$

Using the identities: $\ln l_{T}^{*}=\ln l^{*} \frac{l^{*}}{l_{T}^{*}}-\ln l_{N}^{*} \frac{l_{N}^{*}}{l_{T}^{*}}$ and $\ln l_{N}^{*}=\ln l^{*} \frac{l^{*}}{l_{N}^{*}}-\ln l_{T}^{*} \frac{l_{T}^{*}}{l_{N}^{*}}$ then

$$
\frac{d \ln e}{d \ln l^{*}}=\gamma\left(\frac{l^{*}}{l_{N}^{*}}-\frac{l^{*}}{l_{T}^{*}}\right)
$$

A demographic shock is represented by $\mathrm{d} \ln l^{*}$, a proportional change in employment. Equation (B2) shows that if new labour is allocated equally between the two sectors, $\frac{l^{*}}{l_{N}^{*}}=\frac{l^{*}}{l_{T}^{*}}$ and hence there is no change in the exchange rate following a demographic shock. 
The allocation of labour between the two sectors depends on their relative marginal products of labour which in turn depends on their relative capital labour ratios.

Note that it is the absolute difference between the shares of new employment allocated between the sectors, and therefore the two capital labour ratios, that determines the response of the exchange rate. Accordingly, if the ratio of aggregate new capital to labour is low then the absolute differences between the capital labour ratios in the two sectors will also be low and therefore the response of the exchange rate will be low. This is the case for developing economies. That is, their capital labour ratios are low and therefore their exchange rate response to a demographic shock is small. 


\section{References}

Ahituv, A. (2001), "Be Fruitful or Multiply: On the Interplay Between Fertility and Economic Development”, Journal of Population Economics, 14, 51-71.

Barro, R. and Sala-I-Martin, X. (1995), “Economic Growth”, McGraw-Hill, New York.

Borsch-Supan, A. (1996), “The Impact of Population Ageing on Savings, Investment and Growth in the OECD Area", in "Future Global Capital Shortages", OECD, Paris, 103-142

Carroll, C. D., Overland, J. and Weil, D, N. (1997), "Comparison Utility in a Growth Model", Journal of Economic Growth, 2, 339-367

Cutler, D.M., Poterba, J.M., Sheiner, L.M. and Summers, L.H. (1990) "An Aging Society: Opportunity or Challenge?" Brookings Papers on Economic Activity, (1), pp.1-74.

Elmendorf, D.W. and Sheiner, L.M. (2000), "Should America Save for its Old Age? Fiscal Policy, Population Ageing and National Saving”, Journal of Economic Perspectives, 14, 3, 57-74.

Fougere, M. and Merette, M. (1998), "Population Ageing, Intergenerational Equity and Growth: Analysis with an Endogenous Growth, Overlapping Generations Model", International Conference on Using Dynamic Computable General Equilibrium Models for Policy Analysis, Denmark, June 14-17

Fougere, M., and Merette, M. (1999) "Population ageing and economic growth in seven OECD countries". Economic Modelling, 16, 411-27.

Fuhrer, J.C. (2000), "Habit Formation in Consumption and Its Implications for Monetary-Policy Models", The American Economic Review, 90, 3, 367-390 
Galor, O. and Hyoungsoo, Z. (1997), "Fertility, Income Distribution, and Economic Growth: Theory and Cross-Country Evidence”, Japan and the World Economy, $9,197-229$

Guest, R. and McDonald, I.M., (2002a), "Vintage Versus Homogeneous Capital in Simulations of Population Ageing: Does it Matter", mimeo.

Guest, R. and McDonald, I.M., (2002b), "Would a Decrease in Fertility be a Threat to Living Standards in Australia”, Australian Economic Review, 35, 1, 29-44

Guest, R. and McDonald, I.M., (2002c), "Population Ageing, Capital mobility and Optimal Saving”, seminar paper presented at Queensland University of Technology, August, 2002.

Hondroyiannis, G. and Papapetrou, E. (1999), "Fertility Choice and Economic Growth: Empirical Evidence from the U.S.”, I.A.E.R., 5, 1, 108-120.

International Labour Organisation (ILO)(2001), “Key Indicators of the Labour Market 2001-2002”, ILO, Geneva.

International Monetary Fund (IMF) (2000), “Internationial Financial Statistics Yearbook 2000", IMF, Washington DC.

Masson, P.R. and Tryon, R.W. (1990), “Macroeconomic Effects of Projected Population Ageing in Industrial Countries”, IMF Staff Papers, 37, 3.

McKibbin, W. (1999), "Forecasting the World Economy Using Dynamic Intertemporal General Equilibrium Multi-Country Models”, Brookings Discussion Paper in International Economics, \#145, The Brookings Institution, Washington DC.

McKibbin, W.J. and Nguyen, J. (2001), “The Impact of Demographic Change in Japan Some Preliminary Results from the MSG3 Model", Research School of Pacific and Asian Studies, Australian National University.

Miles, D., (1999) "Modelling the Impact of Demographic Change on the Economy" 
Economic Journal, 109, pp.1-36.

Solow, R.M. (1960), “Investment and Technical Progress”, in Arrow, K., Karlin, A., Suppes, P. (eds.), Mathematical Methods in the Social Sciences, Stanford University Press, Stanford.

Steinman, G., Prskawetz, A. and Feichtinger, G. (1998), “A Model of Escape From the Malthusian Trap", Journal of Population Economics, 11, 535-550

Summers, L.H. and Heston, A. (1993), "Penn World Tables", available at http://www.pwt.econ.upenn.edu/

Turner, D., Giorno, C. DeSerres, A., Vourch, A. and Richardson, P. (1998), "The Macroeconomic Implications of Ageing in a Global Context”, $\underline{\text { OECD }}$ Economic Department Working Papers, 193.

Taylor, J. B. and Woodford, M. (Eds.) (1999), " Volume 1A", Elsevier, Amsterdam.

United Nations (2000), “Long Range World Population Projections. Based on the 1998 Revision", United Nations, New York 2001.

Weil, D. (1999), “Why has fertility Fallen Below Replacement in Industrial Nations, and Will it Last?", American Economic Review, 89, 2, 251-255. 


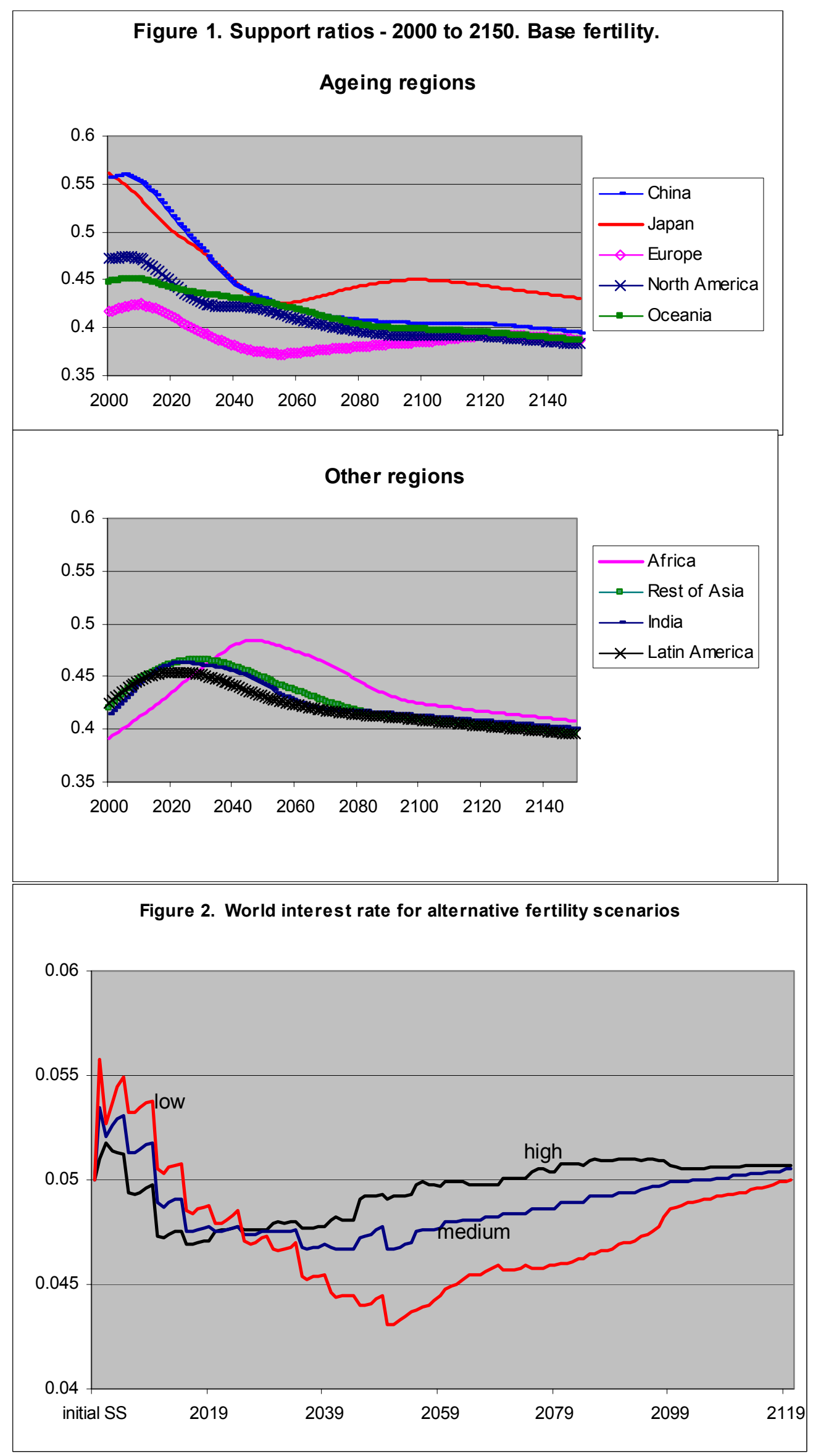


Figure 3. Saving, investment and current account balances
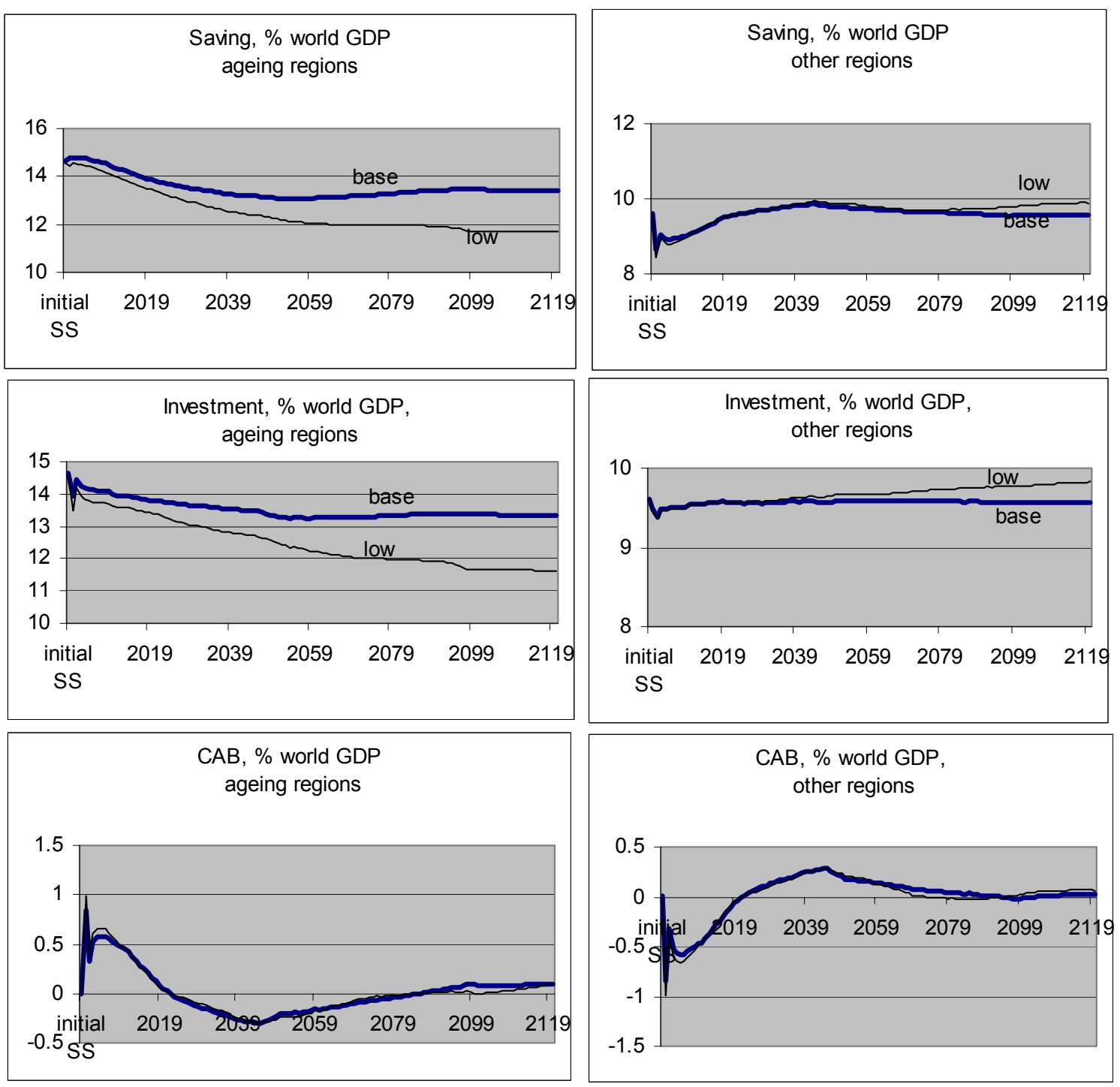
Figure 4a. Living standards of a representative ageing region (Japan) and a representative younger region (Africa) under alternative fertility scenarios

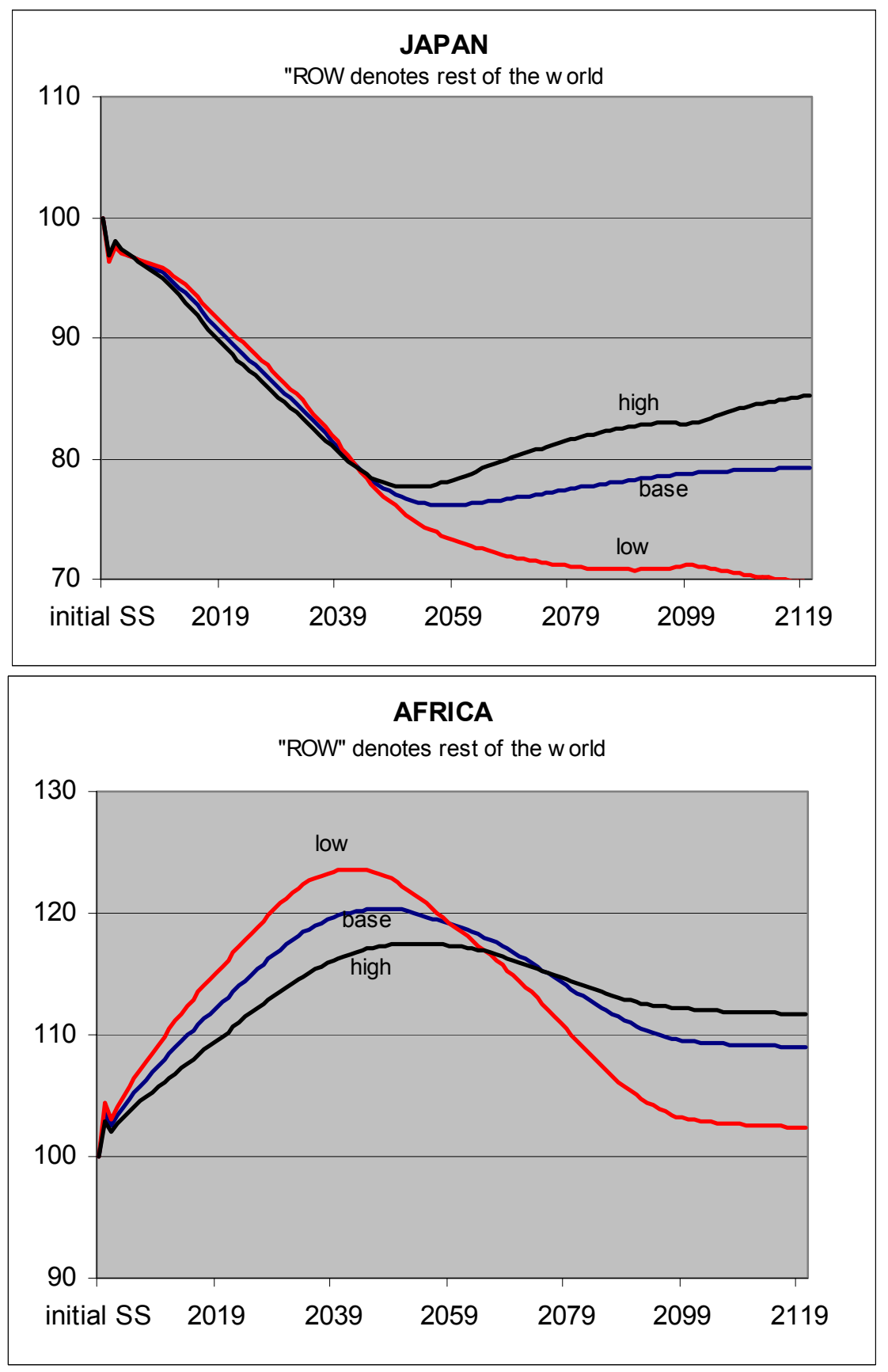


Figure 4b. Effects of alternative fertility rates on living standards of a representative ageing region (Japan) and a representative younger region (Africa). Percentage change relative to base demographics.

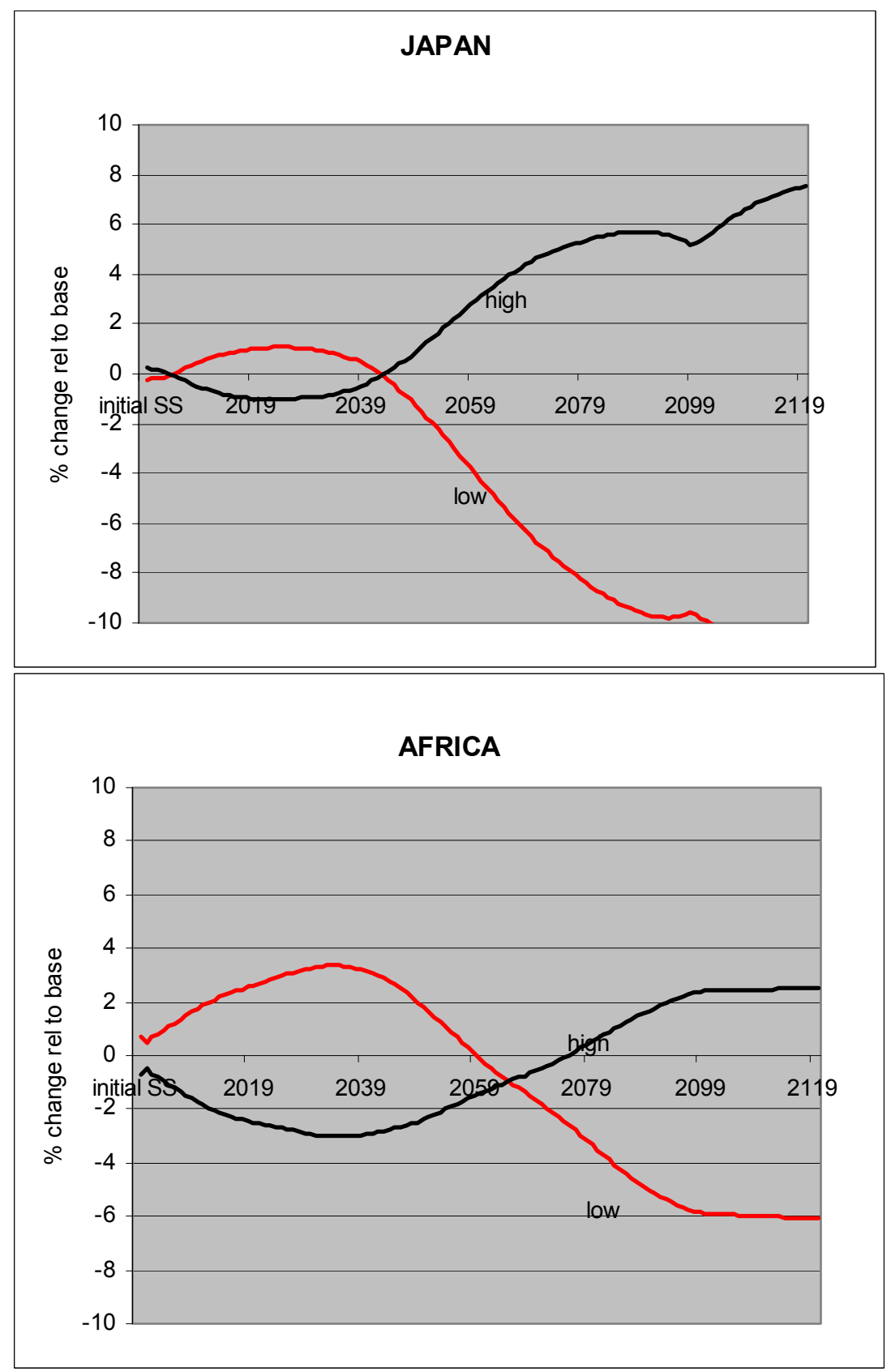


Figure 5. Decomposition of effects of lower fertility rates on living standards of a representative ageing region (Japan) and a representative younger region (Africa)

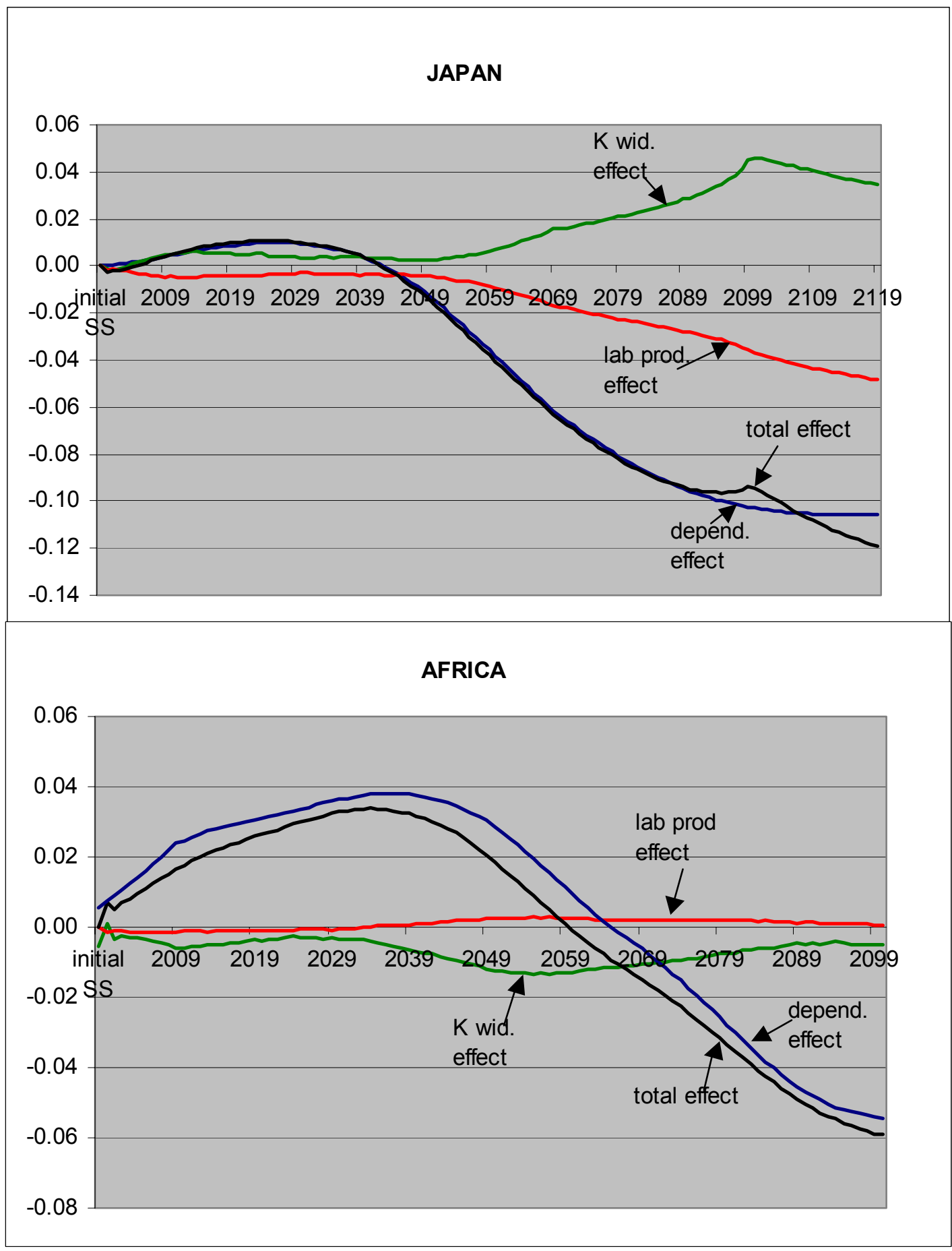




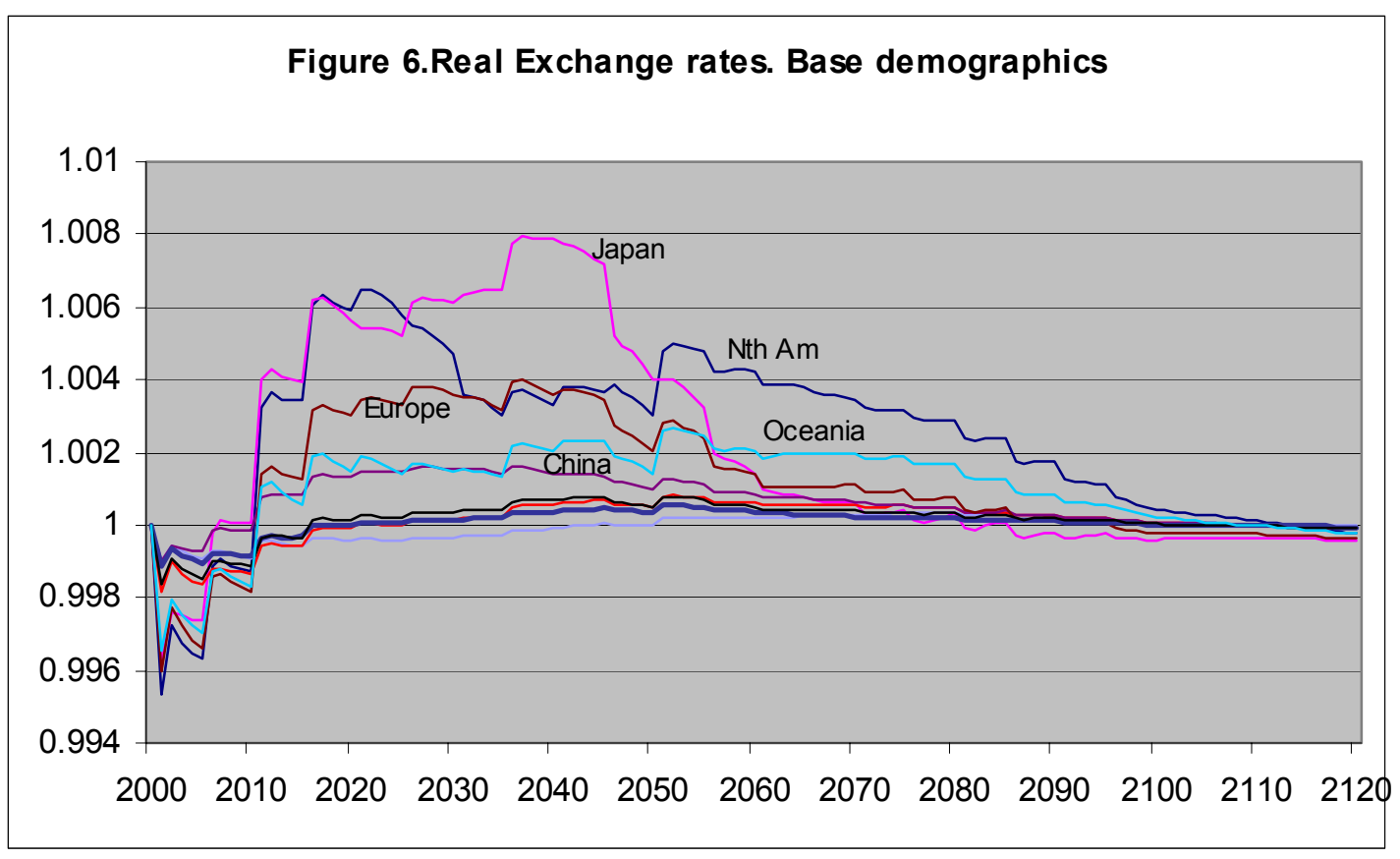

